\title{
Perforation of the capsule of Clisson by migration of a plastic biliary stent during a rendezvous and ERCP procedure
}

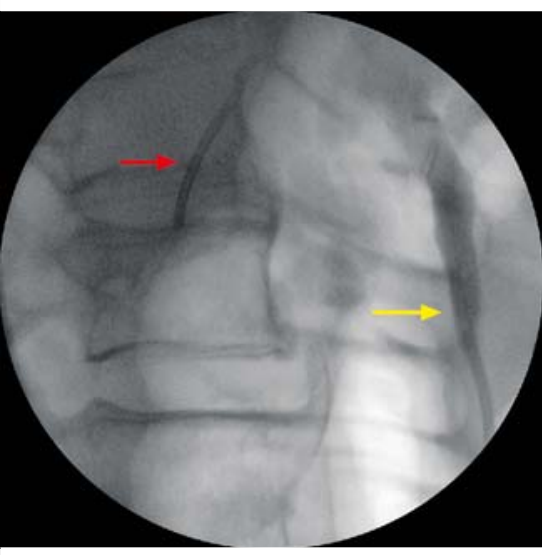

- Fig. 1 Cholangiogram showing proximal migration of the stent (red arrow). A second plastic stent was inserted into the common bile duct to ensure adequate ongoing biliary drainage (yellow arrow).

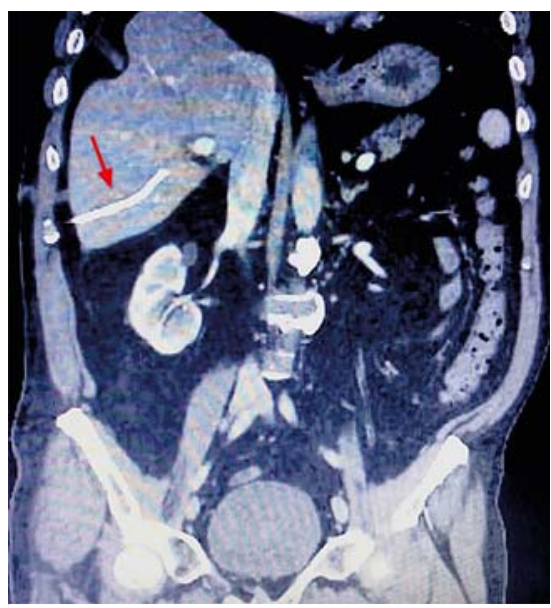

Fig. 2 Computed tomography scan image showing migration of the biliary stent through Glisson's capsule.

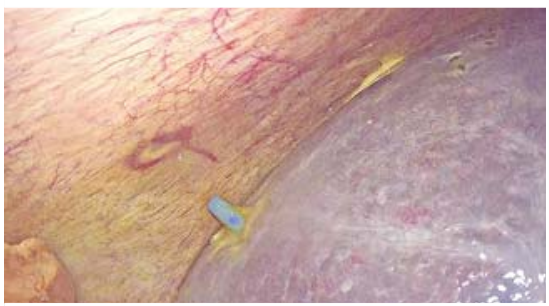

- Fig. 3 Laparoscopic surgery revealed the tip of the stent perforating the hepatic surface.

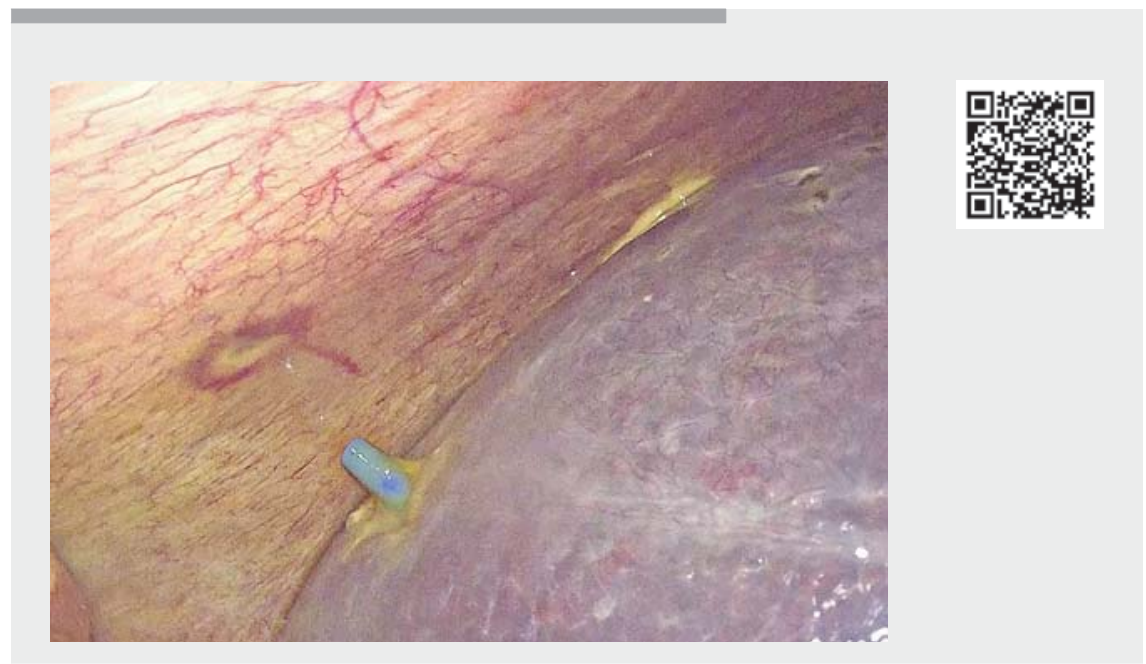

$\checkmark$ Video 1 Rendezvous and endoscopic retrograde cholangiopancreatography procedure leading to perforation of Glisson's capsule by immediate migration of a plastic biliary stent.

Stent migration is a rare complication reported in $5 \%-10 \%$ of cases, with proximal migration being even more infrequent $[1,2]$. Migration causing perforation of intrahepatic structures is exceptional, with only 14 cases reported [3]. We present a case of migrated plastic stent during a rendezvous and endoscopic retrograde cholangiopancreatography (ERCP) procedure, which led to perforation of Glisson's capsule.

A 70-year-old man presented with abdominal pain and jaundice. His medical history included laparoscopic cholecystectomy. Magnetic resonance cholangiography showed multiple choledocholithiasis. ERCP was unsuccessful due to the unstable duodenoscope position and "floppy" papilla. Therefore, a percutaneous rendezvous technique was performed.

After placement of a 0.035 " guidewire (Wilson-Cook Medical, Limerick, Ireland) and sphincterotomy, removal of choledocholithiasis was achieved but papillary fibrosis was observed. Owing to the difficulty of the procedure, a straight-type plastic stent, $5 \mathrm{~cm}$ in length and $8.5 \mathrm{Fr}$ in diameter (Advanix Biliary Stent; Naviflex, Boston, Massachusetts, USA) was placed. However, during stent delivery, firm resistance was observed and, after several back-and-forth movements from both sides of the guidewire, the biliary stent was finally released, although it disappeared from endoscopic view. The cholangiogram showed its migration into the periphery of the right hepatic lobe ( $\triangleright$ Fig. $\mathbf{1})$. A second plastic stent with the same characteristics was placed uneventfully ( $\bullet$ Fig. $\mathbf{1}$ ). The rupture of Glisson's capsule was confirmed by computed tomography scan ( Fig.2). Cholangioscopy-guided stent removal [4] was not available. Emergency laparoscopic surgery showed a small amount of bilioperitoneum and the hepatic surface perforated by the tip of the stent ( $\bullet$ Fig.3), which was removed ( $\vee$ Video 1 ). The clinical outcome was uneventful, and the patient was discharged 4 days later.

These unusual cases of intrahepatic perforation have previously occurred after 
late stent migration, with 5 days being the shortest period of time reported [5]. This report describes immediate stent migration leading to perforation of Glisson's capsule and visualized during ERCP.

Endoscopy_UCTN_Code_CPL_1AK_2AD

\section{Acknowledgment}

The authors thank Marta Martinez Schmickrath for her collaboration in editing this report.

\section{Competing interests}

The authors declare that they have no conflict of interest.

The authors

Paula Fernández-Alvarez ${ }^{1}$, Juan CintasCatena ${ }^{2}$, Victoria A. Jimenez-García ${ }^{1}$, Francisco Bellido Muñoz ${ }^{1}$, Rafael RomeroCastro ${ }^{1}$, Pedro Hergueta-Delgado ${ }^{1}$, Angel Caunedo-Alvarez ${ }^{1}$

1 Gastroenterology and Endoscopy Unit, Virgen Macarena University Hospital, Seville, Spain

2 Colorectal Unit, Department of General and Digestive Surgery, Virgen Macarena University Hospital, Seville, Spain
Corresponding author

Paula Fernández-Alvarez, MD

Gastroenterology and Endoscopy Unit,

Virgen Macarena University Hospital, Doctor

Fedriani, № 3, Sevilla 41009, Spain

paulafer7@gmail.com

\section{References}

[1] Dumonceau J-M, Tringali A, Blero D et al. Biliary stenting: indications, choice of stents and results: European Society of Gastrointestinal Endoscopy (ESGE) clinical guideline. Endoscopy 2012; 44: 277-298

[2] Arhan M, Odemiş B, Parlak E et al. Migration of biliary plastic stents: experience of a tertiary center. Surg Endosc 2008; 23: 769

[3] Ozair A, Ahmad F, Kumar S et al. Transhepatic intraperitoneally migrated biliary stent: a rare finding during laparoscopic cholecystectomy. J Minim Access Surg 2021; 17: 85-87

[4] Bills G, Brown J, Gabr M. Cholangioscopyguided removal of a proximally migrated biliary stent using a modified standard polypectomy snare. VideoGIE 2021; 6: 316-318

[5] Richenberg JI, Amin Z, Hatfield AR et al. Pleurobiliary fistula following Tannenbaum biliary stent insertion. Eur Radiol 1996; 6: 697-699
Bibliography

Endoscopy 2022; 54: E458-E459

DOI 10.1055/a-1625-4401

ISSN 0013-726X

published online 27.9.2021

(c) 2021. Thieme. All rights reserved.

Georg Thieme Verlag KG, Rüdigerstraße 14,

70469 Stuttgart, Germany

\section{ENDOSCOPY E-VIDEOS}

https://eref.thieme.de/e-videos

回屌 Endoscopy E-Videos is an open access online section, 回舴: reporting on interesting cases and new techniques in gastroenterological endoscopy. All papers include a high quality video and all contributions are freely accessible online. Processing charges apply (currently EUR 375), discounts and wavers acc. to HINARI are available.

This section has its own submission website at https://mc.manuscriptcentral.com/e-videos 